\title{
KONTRIBUSI ILMU TASAWUF DALAM PEMBANGUNAN KARAKTER BANGSA
}

\author{
Asmaran As \\ Jurusan Psikologi Islam Fakultas Ushuluddin dan Humaniora \\ IAIN Antasari Banjarmasin
}

\begin{abstract}
Sufism is a pure consciousness that is able to direct the human's soul to be good one and has a noble attitude and one of the most things in determining of a person's behavior is the one's own desires. Lust basically should not be turned off, but it must be controlled and directed to conduct an appreciable act. In order to make the soul has such a feeling, it takes hard efforts to turn the nature on that Allah swt has given since he was still in the spiritual realm. In character development, the people in Sufism said that there are stages that must be passed are tathahbur, tahaqquq and takhalluq, or in other terms with similar meaning, namely takhalli, tahalli, and tajalli.
\end{abstract}

Kata kunci: tasawuf, disposisi, karakter.

\section{Pendahuluan}

Secara yuridis, persoalan karakter atau moralitas ini menjadi perhatian yang serius dari para pendiri bangsa ini. Hal ini terlihat pada sila kedua dari Pancasila, yakni: "Kemanusiaan yang adil dan beradab." Juga terlihat pada pada salah satu bait lagu kebangsaan Indonesia Raya, yang berbunyi: "Bangunlah jiwanya bangunlah badannya." Jika dilihat isi UU RI Nomor 20 Tahun 2003 tentang Sistem Pendidikan Nasional, persoalan karakter ini menjadi salah satu tujuan yang ingin dicapai dari pendidikan tersebut, seperti disebutkan: "Pendidikan nasional berfungsi mengembangkan kemampuan dan membentuk watak serta peradaban bangsa yang bermartabat dalam rangka mencerdaskan kehidupan bangsa, bertujuan untuk berkembangnya potensi peserta didik agar menjadi manusia yang beriman dan bertakwa kepada Tuhan Yang Maha Esa, berakhlak mulia, sehat, berilmu, cakap, keratif, mandiri, dan menjadi warga negara yang demokratis serta bertanggung jawab.”

Jika dilihat dari kenyataan yang terjadi di bangsa ini tentu bagi orang yang memiliki kesadaran dan kepekaan moral akan berkata bahwa apa yang dicanangkan oleh pendiri bangsa ini masih dinodai oleh sebagian anak bangsa yang tidak bertanggung jawab. Seperti dapat disaksikan lewat media massa, perilaku korup telah dilakukan mereka yang termasuk elite bangsa, yang seharusnya mejadi teladan dan panutan dalam hal moralitas ini, baik yang ada di lembaga ligeslatif, eksekutif maupun yudikatif. Di sisi lain, di berbagai tempat belakangan ini dapat disaksikan ada kelompok tertentu yang membenarkan tindak kekerasan dengan mengatas namakan agama Islam untuk membungkam orang lain. Islam dijadikan agama pembenaran bagi segenap tindakan yang tidak bermoral dan tidak beradab, Islam tidak lagi sebagai agama rahmat bagi alam semesta. 
Sesungguhnya Islam sangat mementingkan soal moral ini dan juga ternyata setiap ajaran Islam selalu terkait dengan soal moral ini. Sebagai misal dalam ibadah salat Allah SWT menegaskan: ...dan dirikanlah salat, sesunggubnya salat itu mencegah dari perbuatan keji dan mungkar. (Qs. Al-Ankabut [29]: 45). Dalam hal zakat Allah SWT berfirman: Ambillab (bai Mubammad) sebagian dari harta mereka (orang-orang yang mampu demi untuk kamu kasibkan dan sucikan (jiwa-jiwa dan harta benda mereka) dengannya. (Qs. Al-Taubah [9]:102). Dalam kaitannya dengan puasa Allah berfirman: Hai orang-orang yang beriman diwajibkan kepadamu melaksanakan puasa sebagaimana diwajibkan atas orang-orang sebelum kamu agar kamu menjadi orang yang bertakwa. (Qs. Al-Baqaran [2]: 183). Demikian pula dalam hal pelaksanaan haji, orang yang sedang berhaji dilarang berkatakata yang tidak bermanfaat, berbuat fasik dan berbantah bantahan (Qs. Al-Baqarah [2]: 197)). Jika dilihat dari kandungan kitab suci al-Qur'an lebih jauh, tampak sekali persoalan moral (moral baik) menjadi ciri orang yang bertakwa, seperti firman Allah SW'T bahwa orang-orang yang bertakwa itu ialah "orang yang berinfak, baik di waktu lapang maupun sempit, dan orang-orang yang menahan amarahnya dan memaafkan (kesalahan) orang lain. Dan Allah mencintai orang yang berbuat kebaikan.(Qs. Ali 'Imran [3]: 134)

Dalam sunah Rasul saw juga banyak disebutkan tentang keterkaitan ibadah dalam dalam Islam dengan persoalan moral ini. Sebagai contoh, Rasulullah saw bersabda: Siapa yang tidak meninggalkan kata-kata dan perbuatan keji, Allab tidak meminta kepadanya untuk meninggalkan makan dan minum (berpuasa). (H.R. Bukhari). Dalam riwayat lain Nabi saw bersabda: Bukanlah puasa itu hanya dari (menahan) makan dan minum saja, tetapi puasa itu juga menahan diri dari berkata sia-sia dan omongan kotor. Jika ada seseoarang memarahi dan mengatakan kamu bodoh, katakanlah padanya: "aku sedang puasa." (H.R. Ibnu Huzaimah). Dalam konteks yang lebih umum Rasulullah pernah bersabda: Demi Allah, dia tidak beriman, demi Allah, dia tidak beriman, demi Allah, dia tidak beriman. Seorang sahabat bertanya: Siapa dia ya Rasulallab? Nabi saw mengatakan: "Orangyang tetangganya tidak aman dari keburukan akblaknya. (H.R. Bukhari).Lebih tegas lagi, Rasulullah saw bersabda: Sesunggubnya aku diutus oleh Allab untuk menyempurnakan keluburan akblak. (H.R. Ahmad).

Melihat kenyataan dan dorongan yang diberikan oleh amanat pendiri bangsa, serta perintah atau anjuran yang disampaikan al-Qur'an dan Hadis Nabi saw, baik secara langsung atau tidak, meniscayakan kita untuk memberikan kontribusi untuk perbaikan karakter bangsa ini sesuai dengan kemampuan masing-masing. Bagi pemeluk agama Islam yang mempunyai kemampuan (memiliki ilmu agama Islam) untuk itu tentu terpanggil untuk menyumbangkan apa yang ia miliki. Salah satu ajaran atau ilmu agama Islam yang diharapkan dapat digunakan untuk memberikan sumbangannya adalah Ilmu Tasawuf. Dalam tulisan ini dicoba diuraikan sekitar kontribusi Ilmu Tasawuf dalam membangun karakter bangsa.

\section{Berkenalan dengan Tasawuf}

Sebelum membahas tentang kontribusi Ilmu Tasawuf dalam pembangunan karakter, tentu perlu dikenal terlebih dahulu apa itu tasawuf. Untuk mengenal tasawuf bisa didekati lewat bahasa (etimologi)), istilah (terminologi) atau dengan mengenal latar belakang sejarah kelahirannya dan juga bisa dengan memahami dasar atau nas yang sering dirujuk sebagai dalil bahwa tasawuf memiliki dasar normatif dari al-Qur'an maupun sunah Rasul saw. 
Ada beberapa pendapat sekitar asal-usul kata tasawuf. Ada yang mengatakan bahwa tasawuf berasal dari kata shafa (bersih, suci atau murni). Maksudnya, bersih kalbu dari selain Allah SWT.Ada lagi yang mengatakan berasal dari kata shaff (saf, baris).Maksudnya, baris terdepan dalam hal mengabdi kepada Allah SWT.Ada pula yang mengatakan berasal dari kata shuffah (serambi masjid).Maksudnya, ketergantungan kepada Allah SWT, karena tempat tersebut ditempati oleh para sahabat yang fakir, yang seluruh jiwa dan raga mereka diserahkan hanya kepada Allah dan Rasul-Nya. Sementara yang lain mengatakan berasal dari kata shuf (bulu domba, wool kasar). Maksudnya, sebagai simbol kesederhanaan dalam kehidupan agar kalbu tetap bersih, tidak terkotori oleh kehidupan duniawi. ${ }^{1}$ Dengan memperhatikan beberapa pendapat di atas dapat dikatakan bahwa salah satu intisari tasawuf adalah kebersihan kalbu dari selain Allah SWT, yang didapat dengan upaya yang sungguh-sungguh mendekat kepadaNya dan tidak tergola oleh selain-Nya.

Secara istilah, terdapat sejumlah batasan tentang tasawuf ini.Untuk medapatkan batasan yang komprehensif, dalam tulisan mengikuti metode yang yang lakukan oleh Ibrahim Basyuni dalam tulisannya Masy'ah al-Tashawwuf al-Islamy.Sebelum mengambil kesimpulan, Basyuni mengelompokkan batasan-batasan yang ada, yang pada abad ketiga Hijrah katanya sudah ada 40 macam, ke dalam tiga kelompok, yaitu: (1) Al-Bidayah (potensi dasar) yang mengandung arti bahwa setiap manusia memiliki potensi dasar yang bersifat fitri untuk selalu ingin dekat dengan Tuhan. (2) Al-Mujahadat (pejuangan) sebagai usaha keras untuk selalu memperbaiki diri agar senantiasa dekat dengan Tuhan, dan (3) Al-Madzaqat (perasaan) dalam arti merasakan kedekatan dengan Tuhan setelah melewati perjuangan yang tulus karena hanya untuk-Nya semata. Setelah mecermati sejumlah definisi yang dikelompokkannya ke dalam pembagian di atas, Basyuni menyimpulkan bahwa tasawauf ialah "Kesadaran yang bersifat fitri yang mengarahkan jiwa yang benar untuk melakukan kegiatan (ibadah) secara sungguh-sungguh hingga mencapai perasaan berhubungan langsung dengan Tuhan sebagai Realitas Mutlak."2

Dalam kaitannya dengan sejarah kelahiran Ilmu Tasawuf, juga terdapat sejumlah pendapat. Ada yang mengatakan bahwa Ilmu Tasawuf lahir karena pengaruh dari ajaran, paham atau ideologi yang sudah lebih dulu ada, seperti ajaran agama Kristen, teori filsafat, unsur India (ajaran Hindu dan Buddha), tradisi Persia dan lainnya. ${ }^{3}$ Kalau ditelusuri secara cermat dari sejarah Islam, dapat dikatakan bahwa tasawuf sebagai pengamalan telah lahir sejak kelahiran Islam itu sendiri tanpa pengaruh dari ajaran atau paham dari unsur lain. Sebagai ilmu, Ilmu Tasawuf, boleh jadi ada pengaruh dari non Islam, baik itu yang masih bisa diterima (ortodoks / mu'tabarab) karena hanya memperkaya nuansa dan metodologi, ataupun yang tidak bisa diterima (heterodoks/ghairu mu'tabarah) karena sudah menyimpang dari ajaran yang benar. Dalam konteks ini Trimingham mengatakan: "Tasawuf berkembang secara wajar dalam batas-batas Islam. Sekalipun ia menerima pancaran kehidupan dan pemikiran asketisisme Kristen Timur, namun para sufi itu tidak mengadakan kontak-kecuali sedikit-dengan sumber-sumber yang bukan Islam." 4

\footnotetext{
${ }^{1}$ Asmaran As., Pengantar Studi Tasawnf,(Jakarta:PT RajaGrafindo Persada, 2002), h.42-45.

${ }^{2}$ Ibrahum Basyuni, Nasy'ah al-Tashawnuf al-Islamy, (Kairo: Dar al-Fikr,1969), h.17-24.

${ }^{3}$ Asmaran As., Pengantar Studi Tasawuf, h.177-195.

${ }^{4} \mathrm{~J}$. Spencer Trimingham, The Sufi Orders in Islam,(New York: Oxford University Press,1973), h.2.
} 
Dalam konteks sumber normatif ajaran tasawuf, ada sejumlah dalil yang dapat dirujuk. Untuk melihat apa sebenarnya tasawuf, biasa didasarkan pada sebuah Hadis yang menerangkan bahwa ajaran Islam itu dibedakan menjadi tiga bagian, yaitu iman, islam dan ibsan, yang ketiganya ini tidak terpisahkan sebagai bangunan agama Islam (Dien al-Islam). Dalam perkem-bangannya menjadi sebuah ilmu, iman yang diterangkan oleh Hadis tersebut menjadi Ilmu Tauhid atau Ilmu Kalam atau Teologi Islam, islam menjadi Ilmu Fikih atau Hukum Islam, sedangkan ibsan menjadi Ilmu Tasawuf atau Mistisisme dalam Islam. Apa yang disebut dengan ihsan yang menjadi essensi dari Ilmu Tasawuf tersebut, seperti disebut pada Hadis tersebut ialah: "Engkan mengabdi kepada Allah seakan-akan engkau melihat-Nya, seandainya engkau tidak melihat-Nya yakinlah bahwa Allah senantiasa melihat engkau." 5 Dari keterangan Hadis dapat dikatakan bahwa inti dari ajaran tasawuf ialah upaya menghadirkan Tuhan dalam diri seorang pengamal ajaran tasawuf, atau paling tidak merasakan dirinya selalu diawasi Tuhan.Ini tentu dirasakan melalui kesadaran spiritual.Karena itu, dalam kaitannya dengan pembangunan manusia, tasawuf lebih menekankan aspek ruhanimya ketimbang aspek jasmaninya.

\section{Tasawuf dalam Konteks Pembinaan Karakter}

Dalam tulisan ini karakter diterjemahkan ke dalam bahasa dengan istilah khuluq pluralnya akblaq (selanjutnya ditulis dengan istilah baku bahasa Indonesia: akhlak). Dalam Da'irah alMa'arif dikatakan bahwa akhlak ialah "sifat-sifat manusia yang terdidik." ${ }^{6}$ Ahmad Amin mengatakan bahwa akhlak itu adalah "kehendak yang dibiasakan" ("adah al-iradab). Imam alGhazali mendefinisikan: "Akhlak ialah sifat yang tertanam dalam jiwa yang melahirkan macammacam perbutan dengan gampang dan mudah tanpa memerlukan perenungan dan pertimbangan. ${ }^{8}$ Dengan beberapa keterangan ini dapat disimpulkan bahwa akhlak ialah suatu kondisi atau sifat yang telah meresap dalam jiwa dan menjadi kepribadian hingga dari situ melahirkan berbagai macam perbuatan dengan cara spontan dan mudah tanpa dibuat-buat dan tanpa memerlukan pemikiran. Semua ini didapat karena setelah melalui pembinaan atau pembiasaan yang diinginkan.Jadi akhlak atau karakter seseorang pada prinsip dapat dibina, kalau dibina ke arah yang baik akhlaknya menjadi baik, demikian pula sebaliknya. Dalam bahasa Arab, bentuk lahir (al-khalq) ditulis sama dengan bentuk batin (al-khuluq), hanya beda baris (syakal). Kalau bentuk lahir bisa diubah atau dibentuk, maka bentuk batin pun bisa dibentuk atau dididik.

Ada beberapa teori tentang metode yang bisa digunakan untuk membentuk akhlak atau karakter seseorang. Berikut ini dicoba dengan pendekatan Ilmu Tasawuf.

\section{Kembali ke Fitrah}

Menurut ajaran kaum sufi, selama manusia belum bisa keluar dari kungkungan jasmani/ materi, selama itu pula dia tidak akan menemukan nilai-nilai ruhani yang dia dambakan. Untuk itu dia harus berusaha melepaskan ruhnya dari kungkungan jasmaninya.Hal ini harus ditempuh

\footnotetext{
${ }^{5}$ Imam Muslim,Shaheh Muslim bi Syarbi al-Nawawi,I,(Kairo: Al-Mathba'ah al-Mishriyah, t.th), h.157.

"Abdul Hamid Yunus (Ed), Da'irah al-Ma'arif al-Islamiyah, II,(Kairo: Al-Sya'b, t.th), h.436.

${ }^{7}$ Ahmad Amin, Kitab al-Akblaq, (Kairo: Dar al-Kutub al-Mishriyah, t.th), h.15.

${ }^{8}$ Imam al-Ghazali, Ibya' 'Ulum al-Dien,III, (Kairo: Al-Masyhad al-Husain,t.th), h.56.
} 
dengan jalan riyadhah (latihan) yang memerkukan waktu relatif lama.Riyadhah juga bertujuan untuk mengasah ruh supaya tetap suci.Fitrah manusia selalu ingin mencapai yang baik dan membahagiakan dalam mengarungi kehidupannya.Untuk mencapai kebaikan dan kebahagiaan itu dengan mempergunakan ilmu pengetahuan saja, karena ilmu itu adalah produk manusia dan hanya merupakan alat yang terbatas. Manusia akan merasa kehilangan dan kekosongan kalau hanya mengandalkan ilmu materi semata. Jalan menuju kebahagiaan yang hakiki hanya dengan iman yang kukuh, perasaan hidup yang aman bersama Allah SW'T.

Karena kecencerungan manusia itu selalu ingin berbuat baik sesuai dengan nilai-nilai Ilahiyah, maka segala perbuatan yang menyimpang dari padanya merupakan pengingkaran dan melawan fitrahnya. Memang kehidupan yang berlandaskan fitrah yang telah diciptakan Allah pada diri manusia adalah kehidupan yang hakiki. Setiap calon manusia yang akan lahir kedunia, waktu berada di alam arwah, telah mengikat suatu perjanjian dengan Allah sebagaimana fiman-Nya:

Dan (ingatlah), ketika Tuhanmu mengeluarkan keturunan anak-anak Adam dari sulbi mereka dan Allah mengambil kesaksian terhadap jiwa mereka (seraya berfirman): "Bukankah Aku ini Tuhanmu?" mereka menjawab: "Betul (Engkau Tuban kami), kami menjadi saksi". (Kami lakukan yang demikian itu) agar di hari kiamat kamu tidak mengatakan: "Sesungguhnya kami (Bani Adam) adalah orang-orang yang lengah terhadap ini (keesaan Tuhan)

Dengan demikian betapapun atiesnya, musyriknya, jahatnya seseorang, misalnya, pada hakikatnya dia adalah orang yang bertuhan, bertauhid dan orang baik karena ikrar ruhnya dulu dengan Tuhannya. Kalau sekarang dia memperlihatkan diri aties, musyrik atau preman, itu semata-mata penghianatan terhadap ikrar yang pernah dia ucapkan di hadapan Tuhan. Hal ini terjadi karena pengaruh lingkungan yang membentuk pribadinya setelah dia turun ke dunia.

Fitrah merupakan hidayah yang diberikan Tuhan kepada setiap manusia selaku khalifah di muka bumi, yaitu kejadian asalnya yang suci dan baik. ${ }^{9}$ Jadi pada dasarnya manusia adalah makhluk yang suci dan baik, sebab manusia dilengkapi oleh Penciptanya dengan kemampuan dan bakat untuk mengenali sendiri mana hal-hal buruk yang bakal menjauhkannya dari kebenaran, dan hal-hal baik yang mendekatkannya kepada Tuhan. Maka dengan fitrahnya itu manusia menjadi makhluk yang hanif, yaitu yang secara alami cenderung dan memihak kepada yang benar, yang baik dan suci. Allah SWT menegaskan bahwa manusia diciptakan dengan potensi yang hanif seperti firman-Nya:

Maka hadapkanlah wajahmu dengan lurus kepada agama Allah; (tetaplah atas) fitrah Allah yang telah menciptakan manusia menurut fitrah itu. tidak ada peubahan pada fitrah Allah. (Itulah) agama yang lurus; tetapi kebanyakan manusia tidak mengetahui.

Penerjemah dan penafsir al-Qur'an dari Kementerian Agama mendefinisikan bahwa fitrah Allah: maksudnya ciptaan Allah, manusia diciptakan Allah mempunyai naluri beragama yaitu agama tauhid. Kalau ada manusia tidak beragama tauhid, maka hal itu tidaklah wajar.Mereka tidak beragama tauhid itu hanyalah lantara pengaruh lingkungan.

${ }^{9}$ Muhammad al-Ghazali,Khuluq al-Muslim, (Kuwait: Dar al-Bayan, 1970), h.31. 


\section{Pengendalian Hawa Nafsu}

Iman al-Ghazali menyebutkan ada empat macam yang bisa menghalangi seseorang untuk berbuat baik, sekaligus juga dapat menjerumuskannya kepada tindakan yang menyimpang dari yang benar, yaitu dunia dan isinya, makhluk (manusia), syaitan dan hawa nafsu. Dari yang empat tersebut, hawa hafsu yang sangat menentukan karena yang lain tidak bisa berlaku, jika seseorang mampu mengendalikan hawa nafsunya.

Nafsu adalah salah satu potensi yang diciptakan Tuhan di dalam diri manusia hingga ia dapat hidup dan hidup lebih maju, penuh kreatif dan dinamis. Jika manusia tidak mempunyai nafsu tidaklah akan ada kemajuan dalam kehidupan manusia, karena ketiadaan nafsu ini tentu tidak aka nada kompetisi di atara manusia untuk memenuhi tuntutan hidupnya yang selalu berkembang setiap saat, tentu dengan motivasi untuk bisa lebih banyak beribadah kepada Allah SWT.

Jadi sebenarnya, manusia tidak boleh mematikan nafsunya, tetapi dia diharuskan untuk menguasai nafsunya itu hingga dia dapat mengendalikan agar nafsu itu tidak sampai membawanya kepada kesesatan.Menurut tabiatnya, nafsu itu cenderung kepada kesenangan, lupa diri, bermalas-malasan yang membawa kepada kesesatan. Nafsu itu pada tabiatnya memang tidak pernah puas dengan apa yang ia miliki. ${ }^{10} \mathrm{Nabi}$ saw dalam hal nafsu ini pernah bersabda: Sekiranya manusia itu sudah memiliki dua lembah yang penub dengan emas, ia akan minta lembah yang ketiga; dan jika sudah punya tiga, ia minta lagi lembah yang keempat. Demikian seterusnya, nafsu manusia itu tidak. akan pernah merasa cukup sampai ia dimasukekan ke dalam tanah (mati). (H.R. Bukhari). Allah SWT berfirman (Qs. Yusuf [12]:53):

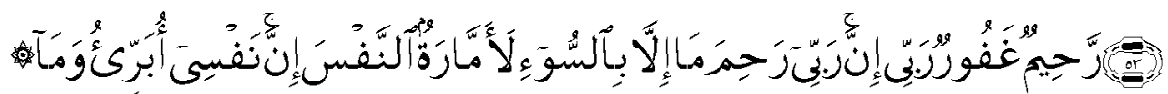

Dan Aku tidak membebaskan diriku (dari kesalahan), karena sesunggubnya nafsu itu selalu menyuruh kepada kejahatan, kecuali nafsu yang diberi rahmat oleb Tubanku.Sesunggubnya Tubanku Maha Pengampun lagi Maha Penyanyang.

Nafsu manusia, sebagaimana diterangkan dalam al-Qur'an yang sering dijadikan dalil oleh orang sufi, juga mempunyai potensi untuk baik dan juga buruk. Nafsu akan menjadi baik jika ia dibersihkan dari pengaruh-pengaruh jahat dengan ajaran-ajaran agama sejak dini untuk mengendalikan nafsu yang jahat (Qs. Al-Syams [91]:7-10). Orang yang tidak dapat mengendalikan hawa nafsunya dikatakan sebagai orang yang telah menuhankan hawa nawa nafsunya sendiri (Qs. al-Jasiyah [45]:23). Orang demikian ini telah menyimpang dari kebenaran (Qs. Al-Nisa'44]:135).

\section{Hanya dengan Amal}

Akhlak atau karakter yang baik pada hakikatnya tidak bisa dicapai tanpa amal, dalam pengertian perbuatan-perbuatan yang mengarah pada pencapaian tingkat-tingkat spiritual, seperti pembersihan jiwa (tąkiyah al-nafs), latihan-latihan spiritual dengan sungguh-sungguh (riyadhadah dan mujahadah) serta pengamalan-pengamalan dari keutamaan-keutamaan moral (fadhai i). Oleh karena itu, dapatlah dimengerti apa yang dikatakan Jalal 1-Din Rumi ketika ia

\footnotetext{
${ }^{10}$ Imam al-Ghazali, Mukasyafah al-Qulub, (Kairo: 'Abd al-Hamid Hanafit.th), h.13.
} 
mengatakan bahwa hanya tasawuflah yang diharapkan mampu mengadakan transformasi jiwa seseorang, bukan Fikih atau pun Kalam, karena baginya Ilmu Fikih dan Ilmu Kalam cenderung kepada formalisme yang lebih menekankan aspek lahir tanpa batin, yang karenanya kebaikan dan keburukan bisa saja muncul. Berbeda dengan fikih dan kalam, tasawuf menekankan amal, lahir dan batin, bagi pencapaiannya. ${ }^{11}$

Tasawuf, seperti kata Reynold A. Nicholson, merupakan salah satu unsur yang vital dalam Islam sehingga tanpa adanya pemahaman mengenai gagasan dan latihan sufistik, kita bersusah payah menelusuri kehidupan keagamaan dalam Islam yang tampak di permukaan saja. ${ }^{12}$ Titus Burckhardt mengatakan bahwa tasawuf tak dapat disebut sebagai sesuatu yang ditambahtambahkan kepada Islam, karena dengan demikian ia akan menjadi sesuatu yang bersifat pinggiran (peripheral) dalam bungungannya dengan sarana-sarana ruhani Islam. ${ }^{13}$ Khan Sahib Khaja Khan mengatakan, kalau Islam dipisahkan dari aspek esoterisismenya (tasawuf), maka ia hanya menjadi kerangka formalitas saja yang akhirnya akan kehilangan keindahan Islam itu sendiri. ${ }^{14}$ Semua yang diungkapkan di atas merupakan pernyataan pengamat yang melihat kenyataan yang terungkap dari pengamal tasawuf, atau pengamal tasawuf sendiri yang merasakan kenikmatan setelah mengamalkan ajaran tasawuf.Memang Imam al-Ghazali pernah mengatakan bahwa tasawuf itu adalah ilmu dan amal. ${ }^{15}$ Di dunia tasawuf sangat popular istilah man lam yadzuq lam yadri (siapa tidak merasa maka dia tidak tahu). Orang yang tahu adalah yang merasakan sendiri lewat pengamalan ilmu ilmu yang telah diketahuinya.

Manusia kata orang sufi memiliki dua rumah, satu rumah jasadnya, yaitu dunia rendah ini. Yang lain rumah ruhnya, yaitu alam yang tinggi. Karena hakikat manusia terletak pada ruhnya, maka manusia merasa terasing di dunia ini, karena alam ruhanilah tempat ruh atau jiwa manusia yang sesungguhnya.Perasaan terasing inilah yang mendorong seseorang menjalani sebuah pencarian mistik, dan dengan itu pula manusia memulai perjalanan spiritual menuju Tuahannya.Namun karena Tuhan sebagai tujuan akhir perjalanan manusia bersifat ruhani, manusia harus berjuang menembus rintangan-rintangan materi agar ruhnya menjadi suci. Penyucian ini penting dalam rangka mendekatkan diri kepada Yang Mahasuci, yaitu Allah SWT, karena Yang Mahasuci hanya bisa didekati oleh yang suci juga. Allah SWT berfirman:

Janganlah kamu bersembahyang dalam mesjid itu selama-lamanya.Sesungguhnya mesjid yang didirikan atas dasar taqwa (mesjid Quba), sejak hari pertama adalah lebih patut kamu sholat di dalamnya. Di dalamnya mesjid itu ada orang-orang yang ingin membersihkan diri.Dan sesungguhnya Allah menyukai orang-orang yang bersih.

Dari keyakian ini, muncullah cara hidup spiritual yang pada prinsipnya bertujuan demi pendekatan pada sumber dan tujuan hidupnya, yaitu Allah SWT. Hal ini bisa mengambil bentuk menyebut-nyebut nama Tuhan, atau yang dikenal dengan istilah zikir, di mana seorang sufi memenuhi jiwanya dengan nama-nama (asma) Tuhan, sehingga dapat merasakan kehadiran

\footnotetext{
${ }^{11}$ Mulyadhi Kartanegara, Menyelami Lubuk Tasawuf, (Jakarta:Erlangga,2006), h.168.

${ }^{12}$ R.A. Nicholson, Studies in Islamic Mysticism, (London: Cambridge University Press, 1921), h.vi.

${ }^{13}$ Titus Burckhardt, An Introduction to Sufi Doctrine, (Lahore: trans lated by D.M. Matheson, SH Muhammad Ashraf,

${ }^{14}$ Khan Sahib Khaja Khan, Studies in Tasamwuf, (New Delhi: Idarah-i Adabiyat-i, 1978), h.ix-x.

${ }^{15}$ Imam al-Ghazali, al-Munqidz min al-Dhalal,(Beirut:Al-Maktabah al-Syu'biyah, t.th), h.68.
} 1973) h.4-5. 
dan kedekatannya; atau dalam bentuk merenungkan dan berulang-ulang membaca firman-Nya dengan penuh kecintaan agar dengan begitu ia dapat memahami kehendak Tuhan dan menghayati hikmah serta pelajaran yang terkandung di dalamnya; atau dengan bentuk bersendirian dengan Tuhan ('uqlah dan khalwah) di tengah malam buta, sambil melapor dan berdoa kepada-Nya (munajat), ketika yang lain sedang tidur lelap, atau apa yang dikenal sebagai qiyam al-lail, sehingga dengan demikian tercapat hubungan intim dan personal dengan Tuhan.

Semua apa yang dipaparkan di atas dapat diamalkan, yang diharapkan akan melahirkan akhlak atau karakter yang baik. Semuanya harus dilakuhan dengan melatih diri (riyadhab) yang dilakukan dengan serius dan sungguh-sungguh (mujahadab). Dampak dari usaha ini diharapkan bembentuk kepribadian (thabi'ah), yang pada puncaknya, agar kepribadian itu bisa langgeng dan lestari, ia menyaksikan wujud Tuhan (musyahadah) kapan pun dan di mana pun dia berada. Dalam konteks ini terdapat ungkapan orang sufi: Syubud al-wabdah fi al-katsrab wa syubud alkatsrah fi al-wahdah (Menyaksikan Yang Satu [Tuhan] pada yang banyak [alam] dan menyaksikan yang banyak pada Yang Satu). Maksudnya, ketika seseorang memandang alam yang beragam ini, ia menyaksikan atau merasakan kehadiran Tuhan padanya, demikian pula ketika dia mengingat Tuhan, ia ingat makhluk-Nya seraya menyayangi dan memperlakukannya sesesuai dengan kehendak Penciptanya. Inilah yang dikehendaki oleh kata ibsan dari Hadis yang disebutkan di atas. Inilah pula yang difirmankan Allah SW'T:

Dan kepunyaan Allah-lah timur dan barat, maka kemanapun kamu menghadap di situlah wajah Allah.Sesunggubnya Allah Maha luas (rahmat-Nya) lagi Maha Mengetabui.

Penerjemah dan penafsir al-Qur'an dari Kementerian Agama menjelaskan yang dimaksud dengan "Disitulah wajah Allah" maksudnya adalah kekuasaan Allah yang meliputi seluruh alam; sebab itu di mana saja manusia berada, Allah mengetahui perbuatannya, karena ia selalu berhadapan dengan Allah. Apa yang disebutkan al-Qur'an tersebut akan dapat dirasakan oleh seseorang ketika ia mengamalkan apa diperintahkan oleh Allah dan menjauhi larangan-Nya.

\section{Akhirnya, karena Hidayah Allah SWT}

Kita wajib berusaha untuk menjadi orang baik yang diredai oleh Allah SW'T. Imam alGhazali di kitabnya Minhaj al-'Abidin, umpamanya, setelah menguraikan 'aqabah (tanjakan atau tingkatan) yang harus ditempuh oleh seorang pengamal ajaran tasawuf (salik/thalib) selalu menutup uraiannya dengan kalimat: Allah lah yang memberi taufik atas kemurahan-Nya; atau dengan kata: Allah lah yang menentukan menurut kehendak-Nya; atau kalimat-kalimat yang senada dengan itu. Ini berarti bagi orang sufi, upaya harus dijalankan tetapi keputusan terakhir ada di tangan Tuhan. Dengan maksud yang praktis, di samping kita harus berusaha, juga harus berdoa. Imam al-Ghazali lebih tegas lagi menekakan: "Sesungguhnya, yang pertama yang harus diperhatikan oleh seorang hamba yang mekhususkan diri untuk beribadah adalah melangkah ke langit (berdoa) dan memohon taufik secara khusus dari Tuhan."16

Seperti diterangkan di atas, usaha yang kita lakukan itu harus dengan latihan yang sungguhsungguh sebagai bukti bahwa kita telah menyiapkan diri untuk menerima hidayah Allah SWT.

\footnotetext{
${ }^{16}$ Imam al-Ghazali, Minhaj al-'Abidin dalam Ihsan Muhammad Dahlan, Siraj al-Thalibin, juz I, (Indonesia:Dar Ihya' al-Kutub al-'Arabiyah, t.th), h.38.
} 
Orang sufi mengibaratkan hidayah itu dengan cahaya (nur). Alat penerima hidayah, yang dimiliki manusia, itu adalah hati (qalbu) yang diibaratkan oleh mereka dengan cermin (mir'ab). Hidayah akan bisa masuk ke dalam hati kalau hatinya bersih, sebagaimana cahaya akan bisa masuk ke dalam cermin kalau cerminnya bersih. Cermin yang bersih mampu menerima cahaya dengan baik, yang pada gilirannya mampu memantulkan cahayanya ke luar dengan baik dan bersih pula. Demikianlah hati manusia, hati yang bersih akan mampu menerima hidayah dengan baik dan memantulkan keluar tingkah laku yang baik pula. Dengan demikian, baik dan buruknya tingkah laku seseorang sebanding dengan bersih dan tidaknya hatinya. Dalam hubungan ini kata al-Ghazali Allah SWT berfirman (Qs. Al-Zumar [39]:22):

Maka apakah orang-orang yang dibukakan Allab hatinya untuk (menerima) agama Islam lalu ia mendapat cahaya dari Tubannya (sama dengan orang yang membatu batinya)? Maka kecelakaan yang besarlah bagi mereka yang telah membatu hatinya untuk mengingat Allah.Mereka itu dalam kesesatan yang nyata.

Nabi saw, kata al-Ghazali, menerangkan dalam kaitannya dengan ayat ini: "Sesunggubnya cahaya itu jika ia masuk ke dalam maka hati menjadi luas dan lapang."

Oleh karena itu, para sufi telah menunjukkan bagaimana caranya membersihkan hati itu dalam sebuah penyucian yang dimulai dengan: (1) tathahbur, yaitu membersihkan diri dari segala kotoran atau penyakit hati; (2) tahaqquq, yaitu menanamkan sifat-sifat terpuji mengganti sifatsifat tercela; dan terakhir (3) takhalluq, yaitu menirukan segala sifat-sifat terpuji dari Rasulullah saw; atau nama-nama yang indah dari Allah SWT. Dalam istilah yang berbeda, tetapi tujuannya sama, tahap-tahap itu dinamakan oleh para sufi dengan istilah-istilah takhalli, tahalli dan tajalli.

Perlu disadari, meskipun begitu lama, berat dan penuh kesungguhan melakukan sesuatu yang dianjurkan, bahwa pelimpahan cahaya Ilahi ke dalam hati seorang hamba pada hakikatnya tidak diusahakan sepenuhnya oleh manusia.Kewajiban seorang hamba hanyalah mempersiapkan (membuka jendela hati dan membersihkannya) agar cahaya bisa masuk ke dalamnya. Sedangkan kapan dan bagaimana, datang dan tidaknya cahaya itu tergantung pada kehendak dan kemurahan Yang Mahakuasa, Sumber Cahaya dari segala cahaya (Nur al-Anwar).

Datangnya cahaya (iluminasi) dari atas (Tuhan) kadang mudah, kadang begitu sulit. Imam al-Ghazali dalam buku autobiografinya Al-Munqidz min al-Dhalal menceritakan bahwa dia baru mendapat limpahan cahaya setelah 10 tahun mengamalkan ajaran tasawuf. Sebelum datangnya iluminasi itu, hidup al-Ghazali digambarkan penuh dengan kesangsian (syakk), yang diibaratkannya dengan kaum Sofis, yang tidak punya pegangan yang pasti dan tidak menemukan kebahagiaan.Sepertinya dia berada dalam kegelapan. Namun setelah iluminasi atau disebut juga kasyf dilimpahkan ke dalam hatinya, tiba-tiba ia menjadi terang benderang. Inilah kunci segala ilmu atau makrifah (márifab). ${ }^{18}$ Pada saat itu, segala kesangsian yang disebabkan oleh ketidak tahuan hilang seketika. Manakala jalan untuk menuju kebenaran terbentang luas dan terang di hadapannya, cahaya yang diperolehnya begitu terang sehingga ia juga mampu menerangi hati orang-orang lain yang sedang kegelapan (bisa jadi para koruptor dan manusia-manusia amoral). Pada hakikatnya, siapa pun tidak mampu menjadikan orang baik dan berakhlak mulia

\footnotetext{
${ }^{17}$ al-Ghazali, Minhaj al-'Abidin, h.39.
}

${ }^{18}$ Imam al-Ghazali, Al-Munqid₹, h.31. 
jika tidak memberinya. Dalam al-Qur'an disebutkan, Nabi sekalipun tidak bisa menjadikan orang baik, jika Allah SWT tidak menghendakinya, seperti firman-Nya (Qs. Al-Qashash [28]:56):

Sesunggubnya kamu tidak akan dapat memberi petunjuk kepada orang yang kamu kasibi, tetapi Allah memberi petunjuk kepada orang yang dikehendaki-Nya, dan Allah lebih mengetabui orangorang yang mau menerima petunjuk.

Memang demikian pada hakikatnya, namun kita juga yakin bahwa bagi mereka menjalani apa yang diberikan atau ditetapkan oleh Allah SWT dan Rasul-Nya, ia akan mendapatkan jalan yang benar. Alah SWT telah menjanjikan dalam firman-Nya (Qs. Al-Ankabut [29]:69):

Dan orang-orang yang berjihad untuk. (mencari keridhaan) Kami, benar-benar akan Kami tunjukekan kepada mereka jalan-jalan Kami. Dan sesunggubnya Allah benar-benar beserta orang-orang yang berbuat baik.

Dalam ajaran, yang teraplikasi dalam tarekat, perjalanan seseorang untuk mendapatkan petunjuk Tuhan, dia memerlukan seorang petunjuk jalan (mursyid), karena perjalanan itu banyak godaannya, hingga dalam dunia tarekat terdapat ungkapan: "Siapa yang tidak memiliki syekh, guru atau mursyid, maka syaitanlah gurunya." Namun bagi mereka yang telah mengetahui jalan tersebut maka mursyid tidak diperlukan. Tetapi karena sebagian besar manusia tidak mengetahui jalan tersebut, mursyid diperlukan bagi mereka yang hendak meniti jalan spiritual. Karena tanpa seorang mursyid, seseorang yang belum mengetahui jalan bisa saja, bahkan kemungkinan besar akan kesasar dan tidak sampai ke tujuan. Namun perlu disadari bahwa mursyid hanya membimbing kita untuk menghadap Tuhan.Mursyid hanya menghantarkan seorang murid sampai ke pintu gerbang istana Tuhan, apakah Tuhan berkenan menerimanya, itu semuanya atas terserah kepada kehendak-Nya.Artinya, kita harus berusaha menjalaninya dan boleh jadi memerlukan seorang mursyid, tapi akhirnya terserah kepada Tuhan untuk member hidayahNya.

\section{Penutup}

Salah satu ajaran Islam yang diharapkan dapat memberikan kontribusi dalam pembangunan karakter bangsa ialah Ilmu Tasawuf.Tasawuf ialah sebuah kesadaran yang bersifat fitri yang mampu mengarahkan jiwa menjadi orang yang baik dan berakhlak mulia, yang pada gilirannya Allah SWT selalu hadir dalam kehidupannya.Jiwanya, perasaannya dan semua tindakannya selalu dibimbing oleh Allah SWT.Di mana pun dan kapan pun dia berada, dia selalu bersama-Nya. Kalau sudah demikian, dia tidak akan melakukan tindakan yang tidak diredai oleh Allah SWT.

Untuk menjadikan jiwa agar memiliki perasaan yang demikian, dibutuhkan usaha untuk menghidupkan fitrah yang telah diberikan Allah SWT sejak ia masih berada di alam ruhani. Fitrah ini kadang-kadang tenggelam atau tertutup oleh kepentingan-kepentingan duniawi.Salah satu yang paling banyak menentukan tingkah laku seseorang adalah hawa nafsunya sendiri.Nafsu pada dasarnya tidak boleh dimatikan, tetapi harus dikendalikan dan diarahkan untuk melakukan tindakan yang terpuji. Untuk mengendalikan nafsu tidak cukup hanya diberi pengetahuan dan nasehat, tetapi harus dengan mengamalkan apa diperintahkan dan menjauhi yang dilarang. Hal ini hanya bisa berhasil kalau berlatih (riyadhah) dengan sungguh-sungguh (mujahadah) hingga menjadi kepribadian (thabi'ah) dan sampai kepada merasakan kehadiran Tuhan (musyahadah). 
Dalam hal pembangunan karakter ini, tahapan-tahapan yang harus dilewati kata orang sufi adalah: tathahbur, tahaqquq dan takhalluq, atau dalam istilah lain dengan arti yang sama, yaitu: takhalli, tahalli dan tajalli. Kendatipun semua itu telah dilakukan, namun pada hakikat tergantung pada kehendak Allah SWT, apa Dia berikan petunjuk-Nya kepada orang itu, atau tidak. Karena itu, kita hanya wajib berusaha seperti yang diperintahkan-Nya, dan wajib berdoa agar yang kita inginkan diterima-Nya.

\section{DAFTAR PUSTAKA}

Amin, Ahmad, (tth). Kitab al-Aklhlaq, Kairo: Dar al-Kutub al-Mishriyah.

Asmaran As, (2002). Pengantar Studi Tasawuf, Jakarta: PT RajaGrafindo Persada, Bayuni, Ibrahim, 1969.Nasy'ah al-Tashawnuf al-Islamy, Kairo: Dar al-Fikr.

Burckhardt, Titus, (1973). An Introduction to Sufi Doctrine, translated by D.M. Matheson, Lahore: SH Muhammad Ashraf.

Al-Ghazali, Imam,(t.th). Ibya' 'Ulum al-Dien, juz III, Kairo: Al-Masyhad al-Husain.

- Minhaj al-A Abidin, t.th. dalam Ihsan Muhammad Dahlan, Siraj al-Thalibin, juz I, Indonesia: Dar al-Ihya' al-Kutub al-'Arabiyah.

-, (t.th.) Mukasyafah al-Qulub, Kairo: 'Abd al-Hamid Hanafi.

—, Al-Munqidz, min al-Dhalal, Beirut: Al-Maktabah al-Syu'biyah.

Al-Ghazali, Muhammad, (1970). Khuluq al-Muslim, Kuwait: Dar al-Bayan.

Kartanegara, Mulyadhi, (2006). Menyelami Lubuk Tasawuf, Jakarta: Erlangga.

Khan, Khan Sahib Khaja, (1978).Studies in Tasamwuf, New Delhi: Idarah-i Adabiyat-i.

Nicholson, R. A.,(1921). Studies in Islamic Mysticism, London: Cambridge University Press.

Trimingham, J. Spencer,(1973). The Sufi Orders in Islam, New York: Oxford University Press.

Yunus, Abdul Hamid (Ed.), (t.th.). Da'irah al-Ma'arif al-Islamiyah, juz II, Kairo, Al-Sya'b. 